\title{
Catalytic gasification of glycerol in supercritical water
}

\author{
Anna May ${ }^{1}$, Joan Salvadó ${ }^{1,2}$, Carles Torras ${ }^{2}$ and Daniel Montané ${ }^{* 1,2}$ \\ ${ }^{1}$ Department of Chemical Engineering, Rovira i Virgili University - URV \\ Av. Països Catalans 26, 43007 Tarragona - SPAIN \\ ${ }^{2}$ Bioenergy and Biofuels Division, Catalonia Institute for Energy Research - IREC
}

Av. Països Catalans 16, 43007 Tarragona - SPAIN

\begin{abstract}
The conversion of glycerol in supercritical water (SCW) was studied at $510-550^{\circ} \mathrm{C}$ and a pressure of 350 bars using both a bed of inert and non-porous $\mathrm{ZrO}_{2}$ particles (hydrothermal experiments), and a bed of $1 \% \mathrm{Ru} / \mathrm{ZrO}_{2}$ catalyst particles. Experiments were conducted with a glycerol concentration of $5 \mathrm{wt} \%$ in a continuous isothermal fixed-bed reactor at a residence time between 2 and $10 \mathrm{~s}$. Hydrothermolysis of glycerol formed water-soluble products such as acetaldehyde, acetic acid, hydroxyacetone and acrolein, and also gases like $\mathrm{H}_{2}, \mathrm{CO}$ and $\mathrm{CO}_{2}$. The catalyst enhanced the formation of acetic acid, inhibited the formation of acrolein, and promoted the gasification of the glycerol decomposition products. Hydrogen and carbon oxides were the main gases produced in the catalytic experiments, with only minor amounts of methane and ethylene. Complete glycerol conversion was achieved at a residence time of $8.5 \mathrm{~s}$ at $510^{\circ} \mathrm{C}$, and at around $5 \mathrm{~s}$ at $550^{\circ} \mathrm{C}$ with a $1 \mathrm{wt} \% \mathrm{Ru} / \mathrm{ZrO}_{2}$ catalyst. The catalyst was not active enough to achieve complete gasification, since high yields of primary products like acetic acid and acetaldehyde were still present. Carbon balances were between 80 and $60 \%$ in the catalytic experiments, decreasing continuously as the residence time was increased. This was attributed partially to the formation of methanol and acetaldehyde, which were not recovered and analyzed efficiently in our set-up, but also to the formation of carbon deposits. Carbon deposition was not observed on the catalyst particles but on the surface of the inert zirconia particles, especially at high residence time. This was related to the higher concentration of acetic acid and other acidic species in the catalytic experiments, which may polymerize to form tar-like carbon precursors. Because of carbon deposition, hydrogen yields were significantly lower than expected; for instance at $550 \stackrel{\circ}{ } \mathrm{C}$ the hydrogen yield potential was only $50 \%$ of the stoichiometric value.
\end{abstract}

Keywords: supercritical water, catalytic gasification, glycerol, hydrogen production, ruthenium catalyst.

\footnotetext{
* Corresponding author: dmontane@irec.cat, phone and fax: (+34) 977202444
} 


\section{Introduction}

Glycerol is a polyalcohol with several commercial applications in food and cosmetics that may be synthesized chemically from epichlorohydrin derived from propylene [1], or biochemically by microbial fermentation [2]. Nowadays, however, massive amounts of low-purity glycerol are being obtained as byproduct in the manufacture of fatty acids, and mostly in biodiesel production where glycerol represents around $10 \mathrm{wt} \%$ of the plant product [3]. The surplus amount generated from biodiesel is so large - more than 600000 tones in Europe in 2006 [4] that glycerol market price has decreased to less that $0.05 € / \mathrm{kg}[5,6]$. Due to its low purity, crude glycerol from biodiesel cannot be used in cosmetics or food unless a costly refining process is undertaken, and that is why it is usually considered a refuse product. Still, its wide availability and cheap price offer new opportunities for chemistry and energy [3].

Conventional gas-phase catalytic processes have been studied for the conversion of glycerol into acrolein $[7,8]$ and a wide variety of glycerol-derived chemicals, as reviewed recently by Zhou and co-workers in a comprehensive paper [9]. Hydrothermal chemistry in sub- or supercritical water (SCW), either non-catalytic or with the addition of homogeneous and heterogeneous catalysts, has received considerable attention in recent years. Non-catalytic hydrothermal processing yields a variety of aldehydes, alcohols and gases [10], but adequate catalysts and control of reaction conditions maximize the yield of specific products like acrolein $[11,12]$.

Gasification of glycerol for the production of hydrogen and syngas is the main application that has been explored for energy purposes. Hydrogen, methane and syngas have been produced by hydrothermal gasification of biomass substrates and model compounds such as glucose, cellulose and lignin in supercritical water [13-18], and glycerol gasification has been investigated as well $[10,19]$. Supercritical water has particular properties that provide a highly reactive and homogeneous medium for the conversion of organic molecules. SCW is miscible with organic compounds and gases due to its low dielectric constant and weaker hydrogen bonds than liquid water, but simultaneously facilitates the occurrence of ionic chemistry due to its relatively high ion product. Mass transfer limitations and coke formation on catalyst surfaces are also reduced because of a low viscosity and high diffusivity [20]. Two approaches have been undertaken for the SCW gasification of glycerol: high-temperature SCW gasification at reaction temperatures ranging from 550 to $800{ }^{\circ} \mathrm{C}$ - with the occasional addition of non-metallic catalyst [21] - and low-temperature catalytic SCW gasification using a metal-based catalyst, usually below $550^{\circ} \mathrm{C}$. Non-catalytic glycerol decomposition in SCW proceeds through a complex reaction mechanism that is summarized in two competing pathways, ionic and free-radical, whose predominance depends on water density and acidity [10,22]. At low temperature and high pressure (i.e., high water density) a set of ionic reactions forms acetaldehyde, formaldehyde and acrolein as main 
products. At low water density a free-radical pathway leads to the preferential formation of allyl alcohol and methanol. Gases are typical products of the free-radical reactions, and their yield is favored by low water density. Most studies on hydrogen production through non-catalytic processing of glycerol, glucose and other biomass model compounds have been conducted at high-temperature since complete gasification is achieved only above $700^{\circ} \mathrm{C}$. However, hydrogen is not favored as the main product and even if gasification efficiency is high with diluted glycerol solutions, it decreases dramatically when the substrate concentration is above $20 \mathrm{wt} \%$ because of the dominance of condensation reactions between glycerol decomposition products that lead to the formation of tarry materials and char $[23,24]$.

Solid catalysts have been studied to promote gas formation at lower temperature, maximize hydrogen selectivity and decrease the formation of tars and char [23]. Carbon was tested as catalyst on the SCW gasification of several organic feedstocks [24], but the gas yield was still low even at $600{ }^{\circ} \mathrm{C}$. Supported-metal catalysts are the most appropriate for SCW gasification and, among them, those based on noble metals like Ru, Rh or Pt. They do not oxidize at SCW conditions and remain active for long periods of time. Support materials should be stable in the harsh SCW environment. Carbon, zirconia $\left(\mathrm{ZrO}_{2}\right)$, titania $\left(\mathrm{TiO}_{2}\right)$ and $\alpha$-alumina $\left(\alpha-\mathrm{Al}_{2} \mathrm{O}_{3}\right)$ have been usually employed [14]. Ruthenium-based catalysts have been shown to offer the best results for SCW gasification. Complete gasification of lignin and cellulose was achieved to produce methane as the main reaction product [25]. Hydrogen production from cellulose and sawdust was investigated with $\mathrm{Ru} / \mathrm{C}, \mathrm{Pd} / \mathrm{C}, \mathrm{CeO}_{2}$, nano- $\mathrm{CeO}_{2}$ and $(\mathrm{CeZr})_{\times} \mathrm{O}_{2}$ catalysts [26]. $\mathrm{Ru} / \mathrm{C}$ was the most active catalyst. Glycerol was gasified completely and the stoichiometric yield of hydrogen ( $7 \mathrm{~mol} \mathrm{H} / \mathrm{mol}$ glycerol) achieved with a $\mathrm{Ru} / \mathrm{Al}_{2} \mathrm{O}_{3}$ catalyst, although a high reaction temperature $\left(700-800^{\circ} \mathrm{C}\right)$ was needed [27]. In fact, no catalyst capable of reaching complete conversion of glycerol and a hydrogen yield close to the stoichiometric value at a temperature below $550^{\circ} \mathrm{C}$ has been found yet, partially because of the formation of methane as competing final product.

In this paper we focused on the SCW gasification of glycerol over a $\mathrm{Ru} / \mathrm{ZrO}_{2}$ catalyst in the low temperature range. Experiments at incomplete conversion of glycerol were performed both with and without a $\mathrm{Ru} / \mathrm{ZrO}_{2}$ catalyst, and the reaction products were determined and quantified at increasing residence time. The influence of the catalyst on the pathways of glycerol conversion is discussed on the basis of the data gathered. 


\section{Materials and Methods}

\subsection{Materials}

Glycerol (99.5\%, Sharlau) was dissolved in Mili-Q water at the adequate weight ratio and the solution was filtered $(0.2 \mu \mathrm{m}$, Whatman) and degassed under vacuum before use. The solution was stored at $5{ }^{\circ} \mathrm{C}$ and used in less than $48 \mathrm{~h}$ to prevent the growth of microorganisms. Formaldehyde (Sigma Aldrich, 37\%), acetic acid (Riedel-deHaën, $100 \%$ ), acetaldehyde (Fluka, $99.5 \%$ ), hydroxyacetone (Sigma Aldrich, $90 \%$ ), acrylic acid (Acros Organics, $99.5 \%$ ), methanol (Scharlau, $99 \%$ ), allylalcohol (Sigma Aldrich, $99 \%$ ), propionaldehyde (Sigma Aldrich, $97 \%$ ), isopropanol (Sigma Aldrich, $99.5 \%$ ) and acrolein (Fluka, $99 \%$ ) were used as standards to identify and calibrate the peaks in the HPLC chromatograph that was used for the quantification of the condensable reaction products. A calibration mixture of gases $\left(20 \% \mathrm{~N}_{2}\right.$, $1 \% \mathrm{CH}_{4}, 12 \% \mathrm{CO}_{2}, 12 \% \mathrm{CO}, 1 \%$ acetylene, $1 \%$ ethylene, $1 \%$ ethane and $52 \% \mathrm{H}_{2}$ ) and mixtures of $\mathrm{H}_{2}$ and $\mathrm{N}_{2}$ were used for the calibration of the online microGC that was used for the analysis of the gaseous products. $\mathrm{RuCl}_{2} \cdot 3 \mathrm{H}_{2} \mathrm{O}$ (Riedel-deHaën) and zirconia stabilized with calcia (99.4\%, Alfa Aesar) with a particle diameter between 100 and $200 \mu \mathrm{m}$, were used to prepare the catalyst.

\subsection{Preparation and characterization of the $\mathrm{Ru} / \mathrm{ZrO}_{2}$ catalyst}

The catalyst was prepared by incipient wetness impregnation, following literature procedures [28-32]. The support was impregnated with the adequate amount of the precursor aqueous solution and dried at $110^{\circ} \mathrm{C}$ for $24 \mathrm{~h}$. Then the sample was crushed and oxidized at $500{ }^{\circ} \mathrm{C}$ for $4 \mathrm{~h}$, reduced with hydrogen at $400{ }^{\circ} \mathrm{C}$ for $5 \mathrm{~h}$, cooled to room temperature under nitrogen and stored in caped vials until use. The catalyst was characterized by $\mathrm{x}$-ray diffraction in a BrukerAXS D8-Discover diffractometer. The angular $2 \theta$ diffraction range was between 5 and $70^{\circ}$ and the data was collected with an angular step of $0.05^{\circ}$ at $3 \mathrm{~s}$ per step. Surface area analysis was performed by nitrogen adsorption in a Micromeritics ASAP 2020. SEM analysis was performed on a scanning electronic microscope JEOL model JSM-6400. The samples were covered with gold before analyzing. Analysis was at $20 \mathrm{kV}$, in high vacuum and at $16 \mathrm{~mm}$ distance between lens and sample. ESEM analysis of variable pressure was joined with a XR microanalysis in order to determine and quantify the elements with a current of $20 \mathrm{kV}$, spot 4 (electrons ray) and at $10 \mathrm{~mm}$ distance between lens and sample.

\section{$2.3 \mathrm{SCW}$ reactor setup}

The SCW gasification experiments were performed in a tubular fixed bed reactor (Figure 1). The feed stocks, water and glycerol solution (V-101, V-102), were pumped through the system using 
two HPLC pumps (GILSON model 307), (P-101 and P-102) at a flow rate between 0.2 and $5 \mathrm{~mL} / \mathrm{min}$. The ratio of glycerol solution $(10-25 \mathrm{wt} \%)$ to water flow rate was varied from 1:2 to 1:4. The mass flow rates fed to the reactor were calculated from the variation of mass of the liquid bottles by means of two scales (Scalter SBA 52, max. weight $2200 \mathrm{~g} \pm 0.01 \mathrm{~g}$ ). The signals from the scales, and other signals of the system like temperatures, were recorded in a computer with a data acquisition system (Compact Field-Point and LabView software, National Instruments). Water was preheated (HC-101) before entering the reactor. Glycerol at room temperature was injected into the preheated water stream just at the top of the catalyst bed to minimize degradation during preheating. The tubular reactor (R-101) had a diameter of 0.635 $\mathrm{cm}$ and a length of $8.68 \mathrm{~cm}$ (total volume $2.75 \mathrm{~mL}$ ). It was packed with $1-3 \mathrm{~g}$ of catalyst previously diluted with $3-5 \mathrm{~g}$ of inert particles (zirconia support) to improve heat transfer and decrease temperature gradients. The particles were supported onto a stainless steel frit $(10 \mu \mathrm{m}$, $\mathrm{VICl}$ ) and a thermocouple ( $\mathrm{TI}-103)$ was inserted to record the temperature of the catalyst bed. The reactor and the water preheater were mounted inside an electric furnace. After leaving the reactor, the fluid was cooled in a heat exchanger (HC-102) refrigerated with ethylene glycol at $2{ }^{\circ} \mathrm{C}$. The fluid passed then through a metal filter $(10 \mu \mathrm{m}, \mathrm{F}-101)$ to retain possible particles entrained from the bed or formed during reaction. Pressure was maintained with a mechanical backpressure regulator (P-101), placed after the filter. After the expansion through the backpressure regulator, the gas and the liquid were separated in a separator (S-101) that was refrigerated by ethylene glycol at $2{ }^{\circ} \mathrm{C}$ to minimize the loss of volatile compounds through the gas stream. The gas stream was analyzed on-line with a microGC (Agilent 3000). The liquid stream flowed into a flask (V-103) that rested on a scale (Acculab Atilon 2202-I), used to determine its flow rate. Samples of the outlet liquid stream were taken for HPLC and pH analysis.

\subsection{Analytical methods}

The composition of the gas was determined by on-line gas chromatography (Agilent 3000A Micro GC) every four minutes. The molar flow rates of the gas products were calculated based on the molar gas flow of nitrogen that was added to the gas-liquid separator as an internal standard. The Plot $\mathrm{Q}$ column ( $\mathrm{He}$ as mobile phase, $60^{\circ} \mathrm{C}, 1.724$ bar) determined $\mathrm{CO}_{2}$, ethane, ethylene and acetylene; the molecular sieve column ( $\mathrm{Ar}, 100{ }^{\circ} \mathrm{C}, 2.068$ bar) analyzed $\mathrm{CO}, \mathrm{H}_{2}$, $\mathrm{CH}_{4}$ and $\mathrm{N}_{2}$. The injection time was $50 \mathrm{~ms}$, sampling time $20 \mathrm{~s}$, sampling velocity $50 \mathrm{~Hz}$, and analysis time $180 \mathrm{~s}$. Control of the microGC and calculation of the gas composition was performed with the Agilent Cerity software. A quantitative analysis of the unreacted glycerol and the condensable reaction products was carried out by HPLC (Agilent 1100) with a BIORAD Aminex HPX-87H ion exclusion column $(300 \mathrm{~nm} \times 7.8 \mathrm{~mm})$ using $0.5 \mathrm{~mL} / \mathrm{min}$ of a $0.005 \mathrm{M}$ 
solution of sulfuric acid as solvent. The column was held at $30^{\circ} \mathrm{C}$ and the volume injected varied from 1 to $30 \mu \mathrm{L}$. The analysis was performed using a RI detector at $30^{\circ} \mathrm{C}$ and a UV-Vis detector at 200,210, 230, 254 and $280 \mathrm{~nm}$. Chromatograph peaks were identified by comparison of retention time and UV spectra with those of pure compounds. Calibration for the identified compounds was performed by analyzing four different samples of calibration solutions that were prepared in a range that covered the expected concentrations of the reaction samples. The $\mathrm{pH}$ of the liquid samples was also determined at room temperature with a Cyberscan 510 ph-meter (Euteoh Instuments).

\section{Results and Discussion}

\subsection{Hydrothermal treatment of Glycerol in SCW}

A preliminary series of experiments was conducted under hydrothermal conditions to assess the extension of glycerol conversion in supercritical water without the use of a catalyst. The noncatalytic experiments were performed using the empty reactor and with the reactor packed with zirconia particles of very low surface area $\left(\sim 0.1 \mathrm{~m}^{2} / \mathrm{g}\right)$. Particle diameters were between 100 and $200 \mu \mathrm{m}$ and the void fraction of the packed bed was 0.493 . For each data point collected along an experiment the conversion of glycerol, $X$ (equation 1 ), the yield of the identified reaction products, $Y_{j}$ (equation 2), the carbon balance $C B$, (equation 3 ), and the hydrogen yield potential HYP, (equation 4) were calculated. $F_{\text {Gly-0 }}$ and $F_{\text {Gly }}$ are the molar flowrates of glycerol at the reactor inlet and outlet, respectively, $\mathrm{Fj}$ the molar flowrate of any specie at the reactor outlet, $\mathrm{nC}_{\mathrm{j}}$ is the number of carbons in compound $\mathrm{j}$, and $\mathrm{nH}_{2, \mathrm{j}}$ denotes the moles of hydrogen gas that would be formed if species $j$ were completely converted into $\mathrm{H}_{2}$ and $\mathrm{CO}_{2}$ following the stoichiometric equation 5 .

$$
\begin{aligned}
& X[\%]=100 \cdot\left(\frac{F_{G l y-0}-F_{G l y}}{F_{G l y-0}}\right) \\
& Y_{j}\left[\frac{m o l}{m o l_{\text {Glycerol }}}\right]=\frac{F_{j}}{F_{G l y-0}} \\
& C B[\%]=100 \cdot\left(\frac{3 \cdot F_{G l y}+\sum_{j=1}^{m} n_{C_{j}} \cdot F_{j}}{3 \cdot F_{G l y-0}}\right) \\
& H Y P=\sum_{j=1}^{m} n_{H_{2} j} \cdot F_{j}
\end{aligned}
$$




$$
\mathrm{C}_{x} \mathrm{H}_{x} \mathrm{O}_{z}+(2 x-z) \cdot \mathrm{H}_{2} \mathrm{O} \rightarrow\left(2 x-z+\frac{y}{2}\right) \cdot \mathrm{H}_{2}+x \cdot \mathrm{CO}_{2}
$$

Residence time of the reacting mixture inside the reactor, $\tau$, was estimated with equation 6 , assuming that the density of the reacting mixture approached that of pure water at the temperature and pressure of the experiment. This is a coarse approximation in our case since glycerol concentration was relatively high ( $5 \mathrm{wt} \%$ in the feed), and therefore density of the reaction mixture should be calculated accounting for the change of composition due to the conversion of glycerol and the formation of products. However, this calculation is not straightforward at supercritical conditions and we used this simplified procedure to have an approximate estimation of the residence time. In equation $6, V_{R}$ is the volume of the catalyst bed, $\phi$ is the void fraction of the bed (which is 1 for the empty-tube experiments), $m_{0}$ the mass flow rate of water and glycerol fed to the reactor, and $\rho_{\mathrm{m}, \mathrm{R}}$ is the density of pure water at the reactor conditions of $\mathrm{P}$ and $\mathrm{T}$. The latter was calculated according to Wagner and Kruse [33].

$$
\tau[s]=\frac{V_{R} \cdot \phi \cdot \rho_{m, R}}{m_{0}}
$$

Initial experiments showed that the zirconia particles could be considered chemically inert since there was no significant difference in conversion and yield of products between the experiments performed with the empty tube and those with the zirconia particles. In consequence, all the experiments were conducted using a packed bed of $\mathrm{ZrO}_{2}$ particles, since the hydrodynamics of the system was then equivalent to that of the catalyzed experiments.

Figures 2 to 5 show the evolution of glycerol conversion and the yield of the main reaction products with reaction time at $510^{\circ} \mathrm{C}$ and $550{ }^{\circ} \mathrm{C}$ for the uncatalyzed experiments at 350 bar. Product yields were expressed as mole of product formed per mole of glycerol fed to the reactor, according to equation 6. Hydrothermal processing at $510{ }^{\circ} \mathrm{C}$ on a bed of inert $\mathrm{ZrO}_{2}$ particles gave a conversion of glycerol of around $22 \%$ after $8.5 \mathrm{~s}$. The main reaction products were acetaldehyde, hydroxyacetone and acetic acid, together with minor amounts of allyl alcohol, propionaldehyde and acrolein. Gaseous products comprised hydrogen, carbon oxides and methane. Trace amounts of acrylic acid and ethylene were also detected. This wide variety of products reflects the complexity of the reaction mechanisms involved in the hydrothermal decomposition of glycerol, which can be summarized into the coexistence of competing ionic and free radical pathways [10]. The ionic path dominates at high-water density - low temperature and high pressure - a situation in which the ion product of water is high enough to allow the existence of free protons and hydroxyl ions that may catalyze ionic reactions, and the static dielectric constant of water is high enough to stabilize ionic species and reaction 
intermediates. The free radical decomposition route dominates at low water density - high temperature and low pressure - where ionic chemistry is not favored due to the low dielectric constant of the media and low water ion product. Table I shows relevant properties for the conditions we have covered in our study, which were calculated according to Wagner and Kruse [33]. At $510^{\circ} \mathrm{C}$ and 350 bar the ion product of water is six orders of magnitude lower than for water at room temperature and the dielectric constant is close to that of steam, which indicates that the ionic route will play a minor role in our case and that the free-radical pathway should dominate. The latter is summarized in Figure 6, where a simplified schematic of a more rigorous mechanism [10] is given. Hydrogen transfer reactions form unstable $\cdot \mathrm{CH}_{2} \mathrm{CHOHCH}_{2} \mathrm{OH}$ (Int1) and $\cdot \mathrm{COHCHOHCH} \mathrm{H}_{2} \mathrm{OH}$ (Int2) radicals. The first evolves into propionaldehyde and allyl alcohol, whereas the second is converted into acrolein, acrylic acid and formaldehyde. Radical isomerization also forms $\cdot \mathrm{COH}\left(\mathrm{CH}_{2} \mathrm{OH}\right)_{2}$ radicals (Int3) from Int2, which then evolve into acetaldehyde and acetic acid. Formaldehyde is only an intermediate that leads rapidly to the formation of carbon monoxide, which is transformed to carbon dioxide by the water-gas shift reaction. Methane is formed from $\mathrm{CO}$ and $\mathrm{CO}_{2}$ as a result of methanation reactions. The carbon balance was between 90 to $100 \%$ and most of reaction products were identified, which was supported by values of HYP between 6 and $7 \mathrm{~mol} \mathrm{H}_{2} / \mathrm{mol}$ glycerol. The carbon unaccounted for was attributed to the formation of known products like methanol, formaldehyde [10] and 3hydroxypropanal [22], which could not be measured accurately due to the limitations of our analytical system. No carbon deposits were visible on the $\mathrm{ZrO}_{2}$ particles.

At $550^{\circ} \mathrm{C}$ the rate of glycerol decomposition was increased significantly, and almost complete conversion was achieved with only $8 \mathrm{~s}$. Significant increases in the yields of all reaction products were observed. The yields of acetic acid, acetaldehyde and hydroxyacetone reached a maximum and started to decrease at high glycerol conversion, showing that they were unstable under hydrothermal conditions. The yield of gases increased continuously, especially carbon oxides since they evolved from the decomposition of acetic acid and acetaldehyde through decarboxylation and decarbonilation. The overall reaction rate for glycerol conversion was well described by pseudo-first order kinetics as seen in Figure 2, where the experimental conversions are compared with this model. The rate constants for the hydrothermal decomposition were $0.034 \mathrm{~s}^{-1}$ and $0.385 \mathrm{~s}^{-1}$ at 510 and $550{ }^{\circ} \mathrm{C}$, respectively, which are in agreement with those reported in other studies [10].

The influence of the $\mathrm{Ru} / \mathrm{TiO}_{2}$ catalyst on glycerol conversion and the selectivity towards the different reaction products are discussed in the following section, where results from experiments performed at incomplete glycerol conversion are discussed. 


\subsection{Catalyst characterization}

Low porosity $\mathrm{CaO}$-stabilized $\mathrm{ZrO}_{2}$ particles were used as support to prepare the $\mathrm{Ru}$ catalyst. The support particles were screened and the fraction between 100 and $200 \mu \mathrm{m}$ was selected. The material had a low surface area of $0.1 \mathrm{~m}^{2} / \mathrm{g}$. Figure 7 shows the XRD spectra of the fresh support particles, which reveals two major crystalline phases - tetragonal zirconia $(54.81 \%)$ and cubic calcium zirconium oxide $\left(\mathrm{Ca}_{0.2} \mathrm{Zr}_{0.8} \mathrm{O}_{1.8}, 24.13 \%\right)$ - and a minor phase of monoclinic zirconia $(21.05 \%)$. Stability of the support material under supercritical water (SCW) conditions was investigated by treating samples of the particles at 350 bar at $450{ }^{\circ} \mathrm{C}$ for 22 hours. The treated particles were then analyzed to compare their surface area and x-ray diffractogram with those of the fresh, untreated particles. The crystalline structure of the particles did not change significantly, as seen in Figure 7. Figure 8 shows the SEM images of the surface of fresh and SCW-treated, which show a smooth and non-porous surface in both cases. The particles were chemically stable during the SCW treatment. The water recovered at the reactor outlet during the SCW treatment of the zirconia particles had average concentrations of $0.040 \pm 0.008 \mathrm{ppm}$ of $\mathrm{Zr}$ and $1.074 \pm 0.046 \mathrm{ppm}$ of $\mathrm{Ca}$. The feed water had an undetectable content of $\mathrm{Zr}$ and $0.860 \pm$ $0.012 \mathrm{ppm}$ of $\mathrm{Ca}$. The outlet water also had $0.102 \pm 0.064 \mathrm{ppm}$ of $\mathrm{Ni}$, and $0.077 \pm 0.009 \mathrm{ppm}$ of $\mathrm{Cr}$, showing negligible corrosion of the Hastelloy-made reactor system.

A shell-type catalyst was obtained by incipient wetness impregnation of the $\mathrm{ZrO}_{2}$ particles, where most of the Ru was deposited in the outer surface of the particles due to their low porosity. The BET surface area of the catalyst was $0.8 \mathrm{~m}^{2} / \mathrm{g}$. The SEM image in Figure 8 shows that the surface of the catalyst was rougher and appeared to be more porous than that of the support. The XRD spectra of the $1 \% \mathrm{Ru} / \mathrm{ZrO}_{2}$ catalyst in Figure 7 confirmed the presence of metallic $\mathrm{Ru}$. The $\mathrm{Ru}$ peaks were low and poorly defined which pointed to a high metal dispersion. ESEM microanalysis of the surface supported the formation of a catalyst particle with a shell-type morphology. The $1 \% \mathrm{Ru} / \mathrm{ZrO}_{2}-\mathrm{CaO}$ catalyst had an average surface content of $12.4 \pm 1.7 \%$ of $\mathrm{Ru}$ as measured by ESEM, which indicates that all Ru was distributed in a thin layer on the outer surface and did not penetrate deep inside the particle's core.

\subsection{Catalytic gasification in SCW}

A preliminary series of experiments was developed to assess the stability of the catalyst. Glycerol conversion and the composition of the gas products were monitored for extended periods to determine changes in the activity of the catalyst and product selectivity. For instance, Figure 9 shows the composition of the gas produced with a fresh sample of catalyst with time on stream at 350 bar and $510^{\circ} \mathrm{C}$ and a residence time of $4.0 \mathrm{~s}$. After an initial period of large changes in gas composition the activity of the catalysts tended to stabilize after $5 \mathrm{~h}$ of operation. Figure 9 also shows the stability of the catalyst for an extended experiment at 350 bar and 
$550^{\circ} \mathrm{C}$. The first section corresponded to a residence time of around $7.5 \mathrm{~s}$, in which complete glycerol conversion was achieved. After $1100 \mathrm{~min}$ of operation the feed flow was increased to reduce the residence time to $2.0 \mathrm{~s}$, which resulted on an average conversion of 0.912 when the system did reach a new steady state. Again, around $4 \mathrm{~h}$ were required for stabilization. Therefore, all experiments were performed after the catalyst was stabilized for at least $5 \mathrm{~h}$ at the intended operation conditions.

The use of the $\mathrm{Ru} / \mathrm{ZrO}_{2}$ catalyst enhanced glycerol conversion significantly. Figure 2 shows that near complete conversion was achieved at around $8.5 \mathrm{~s}$ at $510^{\circ} \mathrm{C}$ and 350 bar when the catalyst was used, whereas it was only $22 \%$ in the non-catalyzed experiment at the same temperature. The overall pseudo-first rate constants for the catalytic gasification of glycerol were $0.377 \mathrm{~s}^{-1}$ and at $0.992 \mathrm{~s}^{-1}$ at 510 and $550{ }^{\circ} \mathrm{C}$, respectively, which are significantly higher than the constants of the uncatalyzed experiments.

The catalyst had a notable influence on the selectivity towards the different reaction products. Acetic acid became the main condensable product instead of acetaldehyde. For instance, at $8.5 \mathrm{~s}$ residence time - complete glycerol conversion - the yield of acetic acid grew from 0.015 $\mathrm{mol} / \mathrm{mol}_{\text {Gly }}$ in the non-catalyzed experiments to $0.25 \mathrm{~mol} / \mathrm{mol}_{\text {Gly }}$, while that of acetaldehyde went from 0.045 to $0.15 \mathrm{~mol} / \mathrm{mol}_{\text {Gly. }}$. Hydroxyacetone yield grew from 0.025 to $0.18 \mathrm{~mol} / \mathrm{mol}_{\text {Gly }}$, also below the yield of acetic acid. Concerning minor products, Figure 4 shows that the yields of allyl alcohol and propionaldehyde also increased significantly, but that acrolein was reduced. Permanent gases - shown in Figure 3 - were the major products, and the yields of hydrogen, carbon oxides and methane all increased when the catalyst was used. The catalyst favored both $\mathrm{C}-\mathrm{C}$ cleavage reactions that formed acetic acid and acetaldehyde, and dehydration reactions that formed $\mathrm{C} 3$ products, mainly hydroxyacetone. The catalyst also promoted reforming to form hydrogen, carbon oxides and methane (secondary products), although glycerol was preferentially converted into primary products (i.e. acetic acid, acetaldehyde, hydroxyacetone, etc.), which were then converted into gases at a slower rate. This may be observed in the experiments at $550{ }^{\circ} \mathrm{C}$ (Figures 2 to 4). A glycerol conversion above $95 \%$ was reached in $4 \mathrm{~s}$, when a maximum in acetic acid yield was attained. Notably, the yields of acetaldehyde, hydroxyacetone, and other condensable primary products decreased with residence time in the entire interval covered by the experiment, showing that they were converted into secondary products. The yield of hydrogen was lower than at $510{ }^{\circ} \mathrm{C}$ because more carbon monoxide and methane were formed, thus reducing hydrogen yield. However, gases were not the sole secondary products. Figure 5 shows the carbon balances for the noncatalyzed and catalyzed experiments. At $510^{\circ} \mathrm{C}$ the carbon balance closure in the noncatalyzed experiments was better than $90 \%$, and it was between 70 and $85 \%$ at $550{ }^{\circ} \mathrm{C}$. The carbon unaccounted for was mostly attributed to formaldehyde and methanol - which were not properly recovered nor quantified in our experimental setup - since no carbon formation on the 
surface of the bed particles could be observed, even at the highest temperatures. The hydrogen yield potential (HYP, the yield of hydrogen that could be obtained if all identified products were completely converted into hydrogen and carbon dioxide) is also shown in Figure 5, and it was close to the theoretical value of $7 \mathrm{molH}_{2} / \mathrm{mol}_{\mathrm{Gly}}$ at $510{ }^{\circ} \mathrm{C}$. At $550 \stackrel{\circ}{\circ} \mathrm{C}$ it was below $6 \mathrm{molH}_{2} / \mathrm{mol}_{\text {Gly }}$, but if the missing carbon was assumed to be in the form of acetaldehyde then the HYP value would be close to the theoretical.

The carbon balance closure was significantly lower for the catalyzed experiments. Values of only $80-60 \%$ were obtained, decreasing continuously as the residence time was increased. Although the formation of methanol and formaldehyde represented a fraction of the carbon unaccounted for, the main reason for the poor carbon balance closure was the formation of carbon deposits on the bed. In fact carbon deposits were not observed on the particles of $\mathrm{Ru} / \mathrm{ZrO}_{2}$ catalyst but on the inert $\mathrm{ZrO}_{2}$ particles that were used to dilute the catalyst bed, and eventually caused partial plugging of the bed and pressure build-up during extended experiments when temperature was below $510^{\circ} \mathrm{C}$. This implies that carbon deposits evolved from the primary reaction products through condensation reactions in the aqueous phase that formed tar-like carbon precursors. The formation of tar at temperatures below $600{ }^{\circ} \mathrm{C}$ has been reported for the hydrothermal gasification of glucose. In our case a proton-catalyzed ionic reaction pathway may be considered due to the relative high concentration of acetic acid and other acidic species. However, the low ion product $(\mathrm{kW})$ and static dielectric constant $(\varepsilon)$ of water at the reaction conditions we used - for instance, $\mathrm{kW}$ and $\varepsilon$ were $1.67 \times 10^{-20}(\mathrm{~mol} / \mathrm{kg})^{2}$ and 1.984 at $510^{\circ} \mathrm{C}$ and 350 bar, respectively [33] - point to a more likely free-radical pathway as dominant. The formation of carbon deposits contributed to a lower relative yield of hydrogen. The HYP was from 4.5 to $5.5 \mathrm{molH}_{2} / \mathrm{mol}_{\text {Gly }}$ at $510{ }^{\circ} \mathrm{C}$, and from only 3.5 to around 5 at $550{ }^{\circ} \mathrm{C}$.

\section{Conclusions}

The hydrothermal and catalytic conversion of glycerol has been studied in supercritical water at 350 bar and intermediate temperatures $\left(510\right.$ and $550{ }^{\circ} \mathrm{C}$ ), covering an interval of residence time that gave incomplete conversion of glycerol. The catalyst $-1 \% \mathrm{Ru}$ on $\mathrm{CaO}$-stabilized $\mathrm{ZrO}_{2}-$ augmented the rate of glycerol conversion and favored carbon-carbon scission reactions to form acetic acid and acetaldehyde as the main primary products, while inhibiting the rate of acrolein formation. The catalyst also converted the primary products into gases through reforming, although the rate of reforming was slower than that of the formation of primary products. When the catalyst was used, the higher concentration of acidic species in the fluid prompted the formation of tar-like adducts that lead to the deposition of carbon on the bed - particularly on the surface of the inert particles of $\mathrm{ZrO}_{2}$ that were used to dilute the catalyst particles - and a poor carbon balance. In conclusion, although the $\mathrm{Ru} / \mathrm{ZrO}_{2}$ catalyst presented good stability and 
overall activity, its selectivity towards reforming reactions was not high enough in the intermediate temperature range we studied. From a practical standpoint, low temperature and pressure are desirable in the hydrothermal processing of biomass in supercritical water to reduce the requirements of construction materials and operation costs. Optimization of the properties of the catalyst to enhance the reforming activity at low temperature and the selectivity towards gas products, and the capacity for processing high concentrations of biomass, are key aspects that need to be solved for the implementation of the supercritical water gasification technology.

\section{Acknowledgements}

This research was supported by the Ministry of Science and Innovation of the Spanish Government (project CTQ2008-02491/PPQ), and the Catalan Regional Government (2009SGR-00237). Anna May also acknowledges "la Caixa" for her scholarship. 


\section{References}

[1] Frost \& Sullivan Market Insight. R\&D Creating New Avenues for glycerine (August 4, 2006). Available online at http://frost.com/prod/servlet/market-insight-top.pag?docid= 77264824

[2] Wang Z-X, Zhuge J, Fang H, Prior B.A. Glycerol production by microbial fermentation: A review. Biotechnology Advances. 2001;19:201-223.

[3] Pagliaro M, Ciriminna R, Kimura H, Rossi M, Della Pina C. From Glycerol to Value-Added Products. Angew. Chem. Int. Ed. 2007;46:4434-4440.

[4] Pagliaro M, Rossi M. The future of Glycerol. New Usages for a Versatile Raw Material. RSC Publishing. 2008 (127 pages).

[5] Johnson D.T, Taconi K.A. The Glycerin Glut: Options for the Value-Added Conversion of Crude Glycerol Resulting from Biodiesel Production. Environmental Progress. 2007;26(4):338348.

[6] Miller-Klein Associates 2006. Available on line at: http://www.ruralsementes.com.br/produtos/Impact of Biodiesel Production on the Glycerol Market.pdf

[7] Corma A, Huber G-W, Sauvanaud L, O'Connor P. Biomass to chemicals: Catalytic conversion of glycerol/water mixtures into acrolein, reaction network. Journal of catalysis. 2008;257:163-171.

[8] Chai S-H, Wang H-P, Liang Y, Xu B-Q. Sustainable production of acrolein: investigation of solid acid-base catalysts for gas-phase dehydration of glycerol. Green Chemistry. 2007;9(10):1130-1136.

[9] Zhou C-H, Beltramini J-N, Fan Y-X, Lu G-Q. Chemoselective catalytic conversion of glycerol as a biorenewable source to valuable commodity chemicals. Chemical Society Reviews. 2008;37:527-549.

[10] Bühler W, Dinjus E, Ederer H.J, Kruse A, Mas C. Ionic reaction and pyrolysis of glycerol as competing reaction pathways in near- and supercritical water. Journal of Supercritical Fluids. 2002;22:37-53.

[11] Ott L, Bicker M, Vogel H. Catalytic dehydration of glycerol in sub- and supercritical water: a new chemical process for acrolein production. Green Chemistry. 2006;8:214-220.

[12] Watanabe M, lida T, Aizawa Y, Aida T.M, Inomata H. Acrolein synthesis from glycerol in hot-compressed water. Bioresource Technology. 2007;98:1285-1290.

[13] Kruse A. Supercritical water gasification. Biofuels, Bioprod. Bioref. 2008;2:415-437. 
[14] Elliott D.C. Catalytic hydrothermal gasification of biomass. Biofuels, Bioprod. Bioref. 2008;2:254-265.

[15] Lu Y.J, Jin H, Guo L.J, Zhang X.M, Cao C.Q, Guo X. Hydrogen production by biomass gasification in supercritical water with a fluidized bed reactor. International Journal of Hydrogen Energy. 2008;33:6066-6075.

[16] Yan B, Wei C.H. Hydrogen Production from Organic Compounds by Supercritical Water Gasification. Progress in Chemistry. 2008;20(10):1553-1561.

[17] Yanik J, Ebale S, Kruse A, Saglam M, Yüksel M. Biomass gasification in supercritical water:

II. Efect of the catalyst. International Journal of Hydrogen Energy. 2008;33:4520-4526.

[18] Guo L.J, Lu Y.J, Zhang X.M, Ji C.M, Guan Y, Pei A.X. Hydrogen production by biomass gasification in supercritical water: A systematic experimental and analytical study. Catalysis Today. 2007;129:275-286.

[19] Kambayashi K, Nishi Y. Possibility of hydrogen generation using supercritical water. Proceeding of EcoDesign2003: Third International Symposium On Environmentally Conscious Design and Inverse Manufacturing. Tokyo, Japan. 2003.

[20] Osada M, Hiyoshi N, Sato O, Arai K, Shirai M. Reaction Pathway for Catalytic Gasification of Lignin in Presence of Sulfur in Supercritical Water. Energy \& Fuels. 2007;21:1854-1858.

[21] Matsumura Y, Minowa T, Potic B, Kersten S.R.A, Prins W, van Swaaij W.P.M, van de Beld B, Elliott D.C, Neuenschwander G.G, Kruse A, Antal Jr M.J. Biomass gasification in near- and supercritical water. Biomass and Bioenergy. 2005;29:269-292.

[22] Antal M.J, Mok W.S.L, Roy J.C, Raissi A.T. Pyrolytic Sources of Hydrocarbons from Biomass. Journal of Analytical and Applied Pyrolysis. 1985;8:291-303.

[23] Kong L, Li G, Zhang B, He W, Wang H. Hydrogen Production from Biomass Wastes by Hydrothermal Gasification. Energy Sources. Part A. 2008;30:1166-1178.

[24] Xu X, Matsumura Y, Stenberg J, Antal Jr M.J. Carbon-Catalyzed Gasification of Organic Feedstocks in Supercritical Water. Ind. Eng. Chem. Res. 1996;35:2522-2530.

[25] Osada M, Sato T, Watanabe M, Adshiri T, Arai K. Low-Temperature Catalytic Gasification of Lignin and Cellulose with a Ruthenium Catalyst in Supercritical Water. Energy \& Fuels. 2004;18:327-333.

[26] Hao X, Guo L, Zhang X, Guan Y. Hydrogen production from catalytic gasification of cellulose in supercritical water. Chemical Engineering Journal. 2005;110:57-65.

[27] Byrd A.J, Pant K.K, Gupta R.B. Hydrogen production from glycerol by reforming in supercritical water over Ru/Al2O3 catalyst. Fuel. 2008;87:2956-2960. 
[28] Perkas N, Zhong Z, Chen L, Besson M, Gedanken A. Sonochemically prepared high dispersed $\mathrm{Ru} / \mathrm{TiO} 2$ mesoporous catalyst for partial oxidation of methane to syngas. Catalysis Letters. 2005;103:9-14.

[29] Elmasides C, loannides T, Verykios X.E. Kinetic Model of the Partial Oxidation of Methane to Synthesis Gas Over Ru/TiO2 Catalyst. AlChe Journal.2000;46(6):1260-1270.

[30] Boucouvalas Y, Zhang Z, Verykios X.E. Partial oxidation of methane to synthesis gas via the direct reaction scheme over Ru/TiO2 catalyst. Catalyst Letters. 1996;40:189-195.

[31] Elliott D.C, Hart T.R, Neuenschwander G.G. Chemical Processing in High-Pressure Aqueous Environments. 8. Improved Catalysts for Hydrothermal Gasification. Ind. Eng. Chem. Res. 2006;45:3776-3781.

[32] Li D, Ichikuni N, Shimazu S, Uematsu T. Hydrogenation of CO2 over spayed Ru/TiO2 fine particles and strong metal-support interaction. Applied Catalysis A: general. 1999;180:227-235.

[33] Wagner W, Kruse A. Properties of Water and Steam. Springer-Verlag, Berlin (1998).

Published in: Chemical Engineering Journal, Volume 160, 2010, Pages 751-759 


\section{TABLES}

Table I. Relevant properties of supercritical water (Calculated according to ref. [35]).

\begin{tabular}{cccccc}
\hline & $\begin{array}{c}\text { Temperature } \\
\left({ }^{\circ} \mathrm{C}\right)\end{array}$ & $\begin{array}{c}\text { Pressure } \\
(\mathrm{bar})\end{array}$ & $\begin{array}{c}\text { Density } \\
\left(\mathrm{kg} / \mathrm{m}^{3}\right)\end{array}$ & $\begin{array}{c}\text { lon Product } \\
(\mathrm{mol} / \mathrm{kg})^{2}\end{array}$ & $\begin{array}{c}\text { Dielectric } \\
\text { constant }\end{array}$ \\
\hline Ambient water & 25 & 1 & 997.1 & $1.01 \times 10^{-14}$ & 78.41 \\
Steam & 100 & 1 & 0.590 & $1.08 \times 10^{-66}$ & 1.006 \\
$\begin{array}{c}\text { Supercritical } \\
\text { water }\end{array}$ & 510 & 250 & 87.09 & $2.98 \times 10^{-23}$ & 1.545 \\
& 510 & 350 & 138.0 & $1.67 \times 10^{-20}$ & 1.985 \\
& 550 & 250 & 78.52 & $1.24 \times 10^{-23}$ & 1.458 \\
& 550 & 350 & 119.8 & $4.02 \times 10^{-21}$ & 1.776 \\
\hline
\end{tabular}




\section{FIGURES}

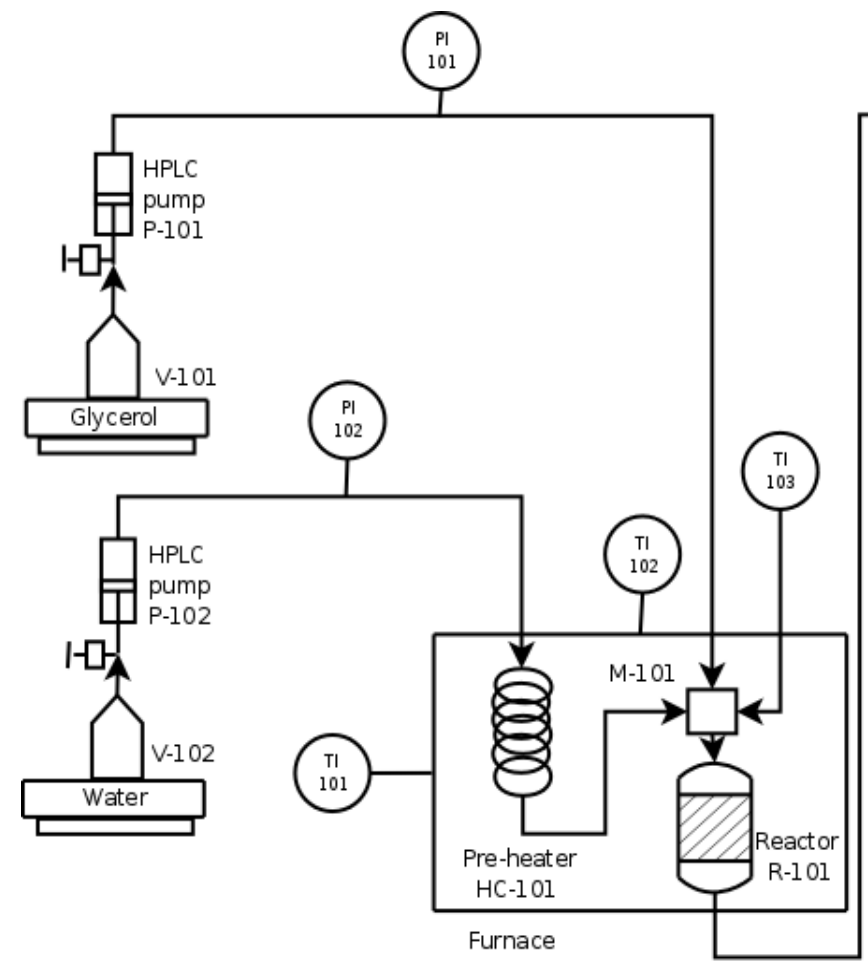

Condenser

HC-102
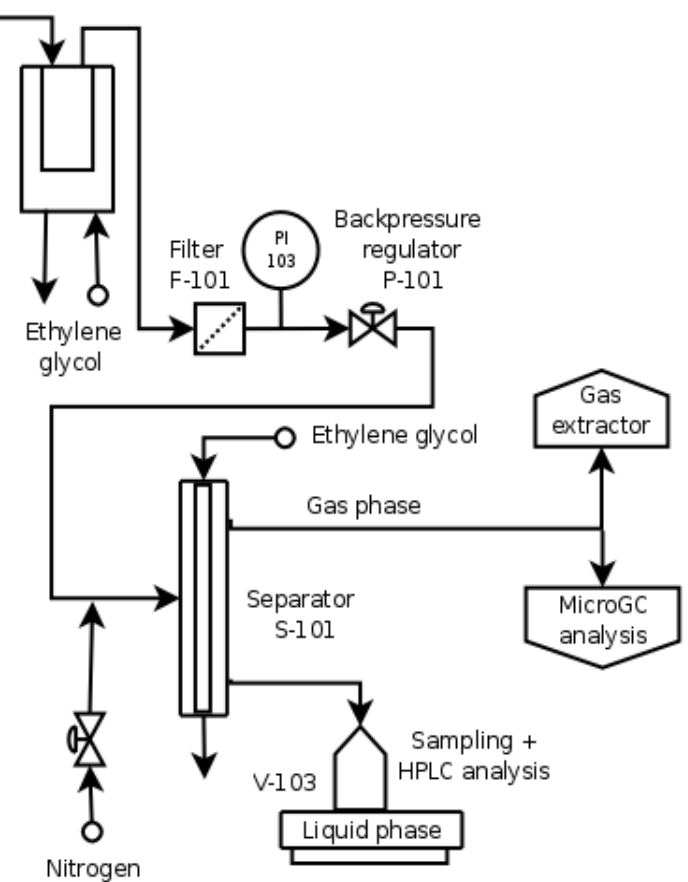

Figure 1. Diagram of the SCW reactor setup. 


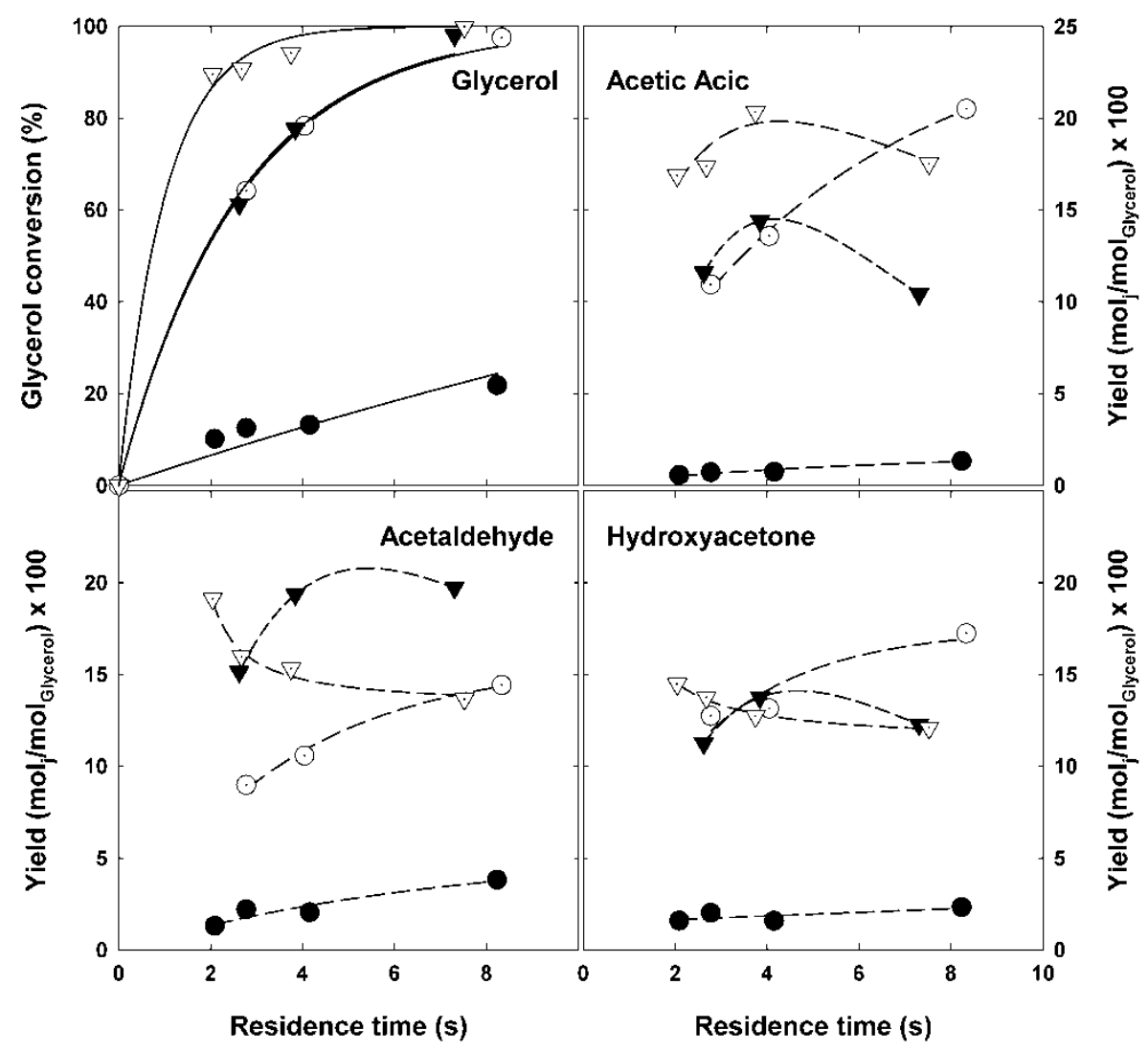

Figure 2. Processing of $5 \%$ glycerol in supercritical water at 350 bar. Glycerol conversion and yields of acetic acid, acetaldehyde and hydroxyacetone in an inert bed of $\mathrm{ZrO}_{2}$ particles (solid symbols), and of $1 \% \mathrm{Ru} / \mathrm{ZrO}_{2}$ catalyst (open symbols) at $510^{\circ} \mathrm{C}(\bullet, \bigcirc)$ and $550^{\circ} \mathrm{C}(\boldsymbol{\nabla}, \nabla)$. 


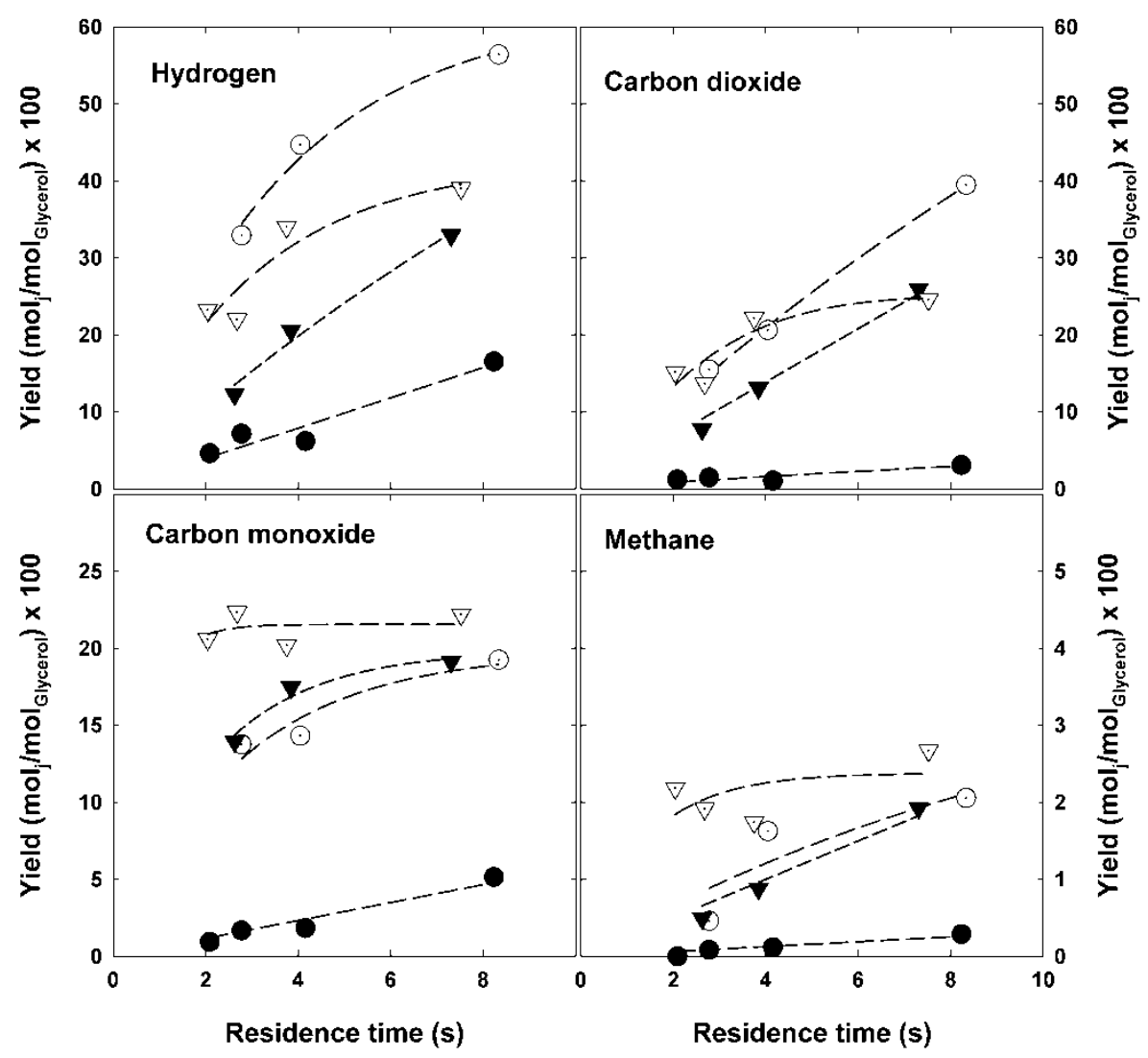

Figure 3. Processing of $5 \%$ glycerol in supercritical water at 350 bar. Yields of hydrogen, carbon oxides and methane in an inert bed of $\mathrm{ZrO}_{2}$ particles (solid symbols), and of $1 \%$ $\mathrm{Ru} / \mathrm{ZrO}_{2}$ catalyst (open symbols) at $510^{\circ} \mathrm{C}(\bullet, 0)$ and $550^{\circ} \mathrm{C}(\boldsymbol{\nabla}, \nabla)$. 


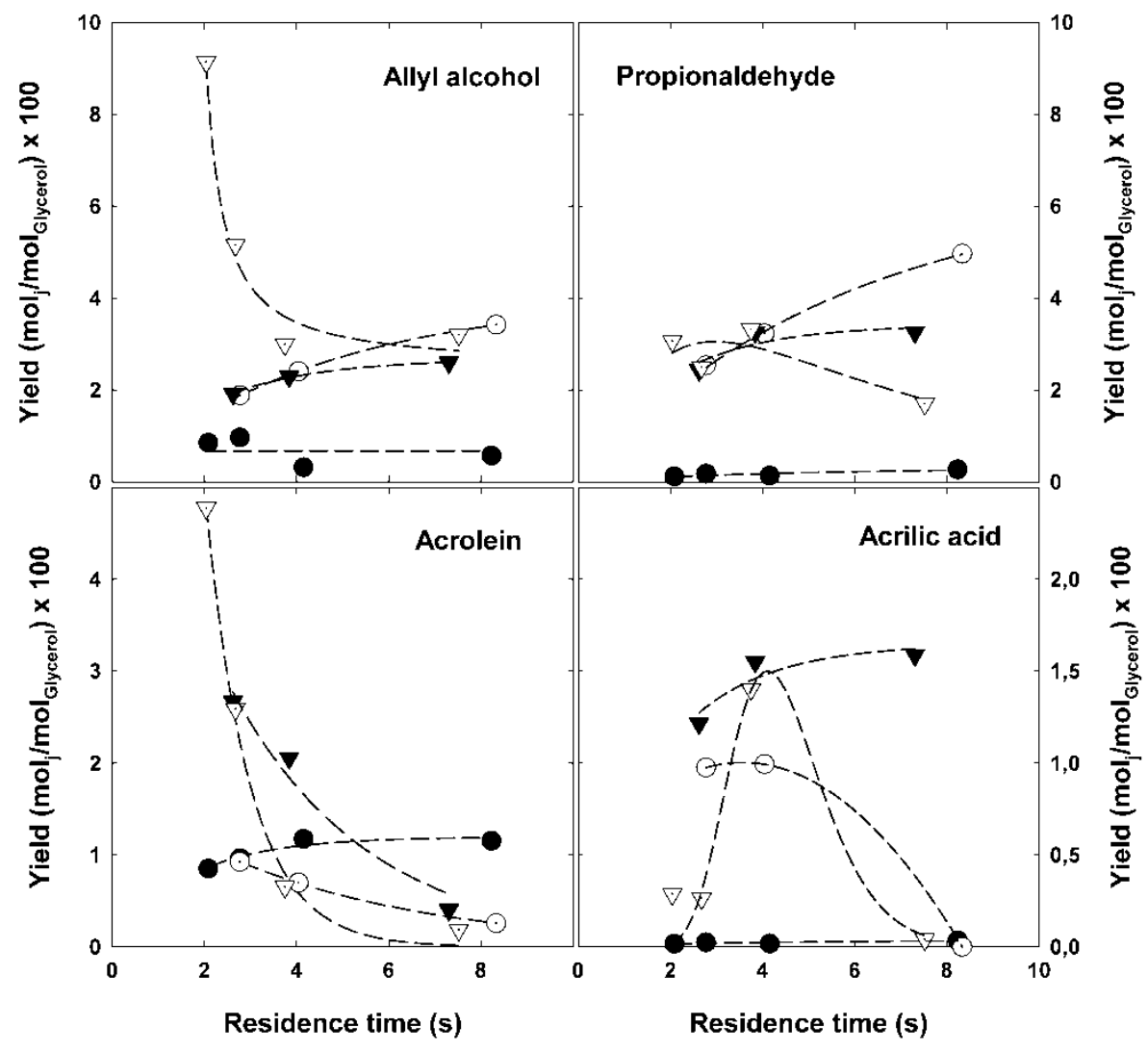

Figure 4. Processing of $5 \%$ glycerol in supercritical water at 350 bar. Yields of allyl alcohol, propionaldehyde, acrolein and acrylic acid in an inert bed of $\mathrm{ZrO}_{2}$ particles (solid symbols), and of $1 \% \mathrm{Ru} / \mathrm{ZrO}_{2}$ catalyst (open symbols) at $510^{\circ} \mathrm{C}(\bullet, \bigcirc)$ and $550{ }^{\circ} \mathrm{C}(\boldsymbol{\nabla}, \nabla)$. 


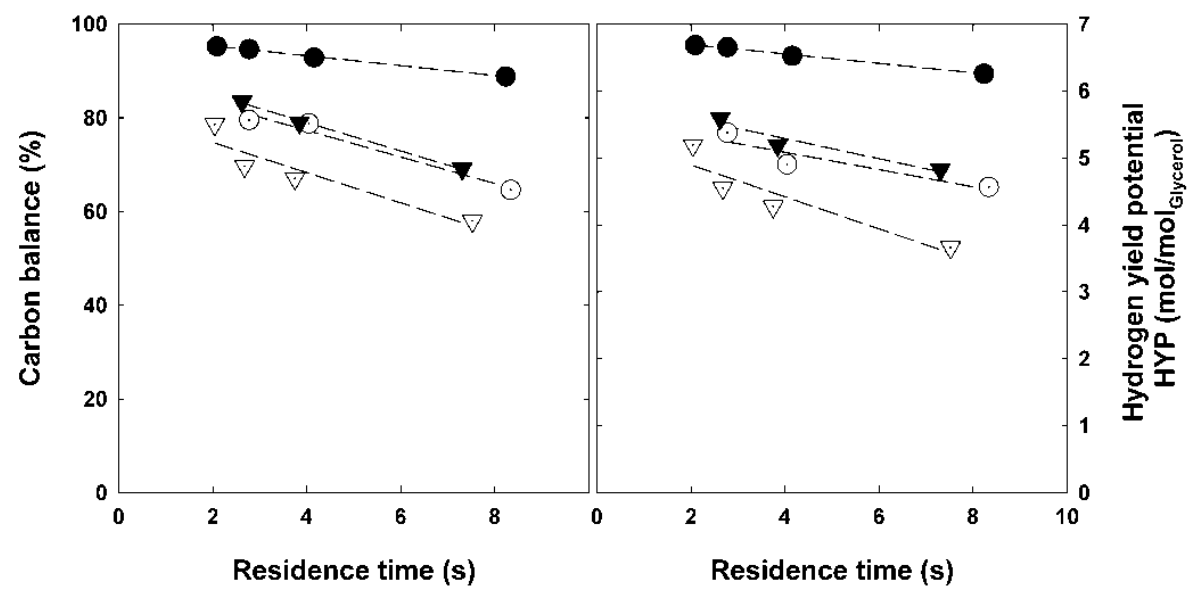

Figure 5. Processing of $5 \%$ glycerol in supercritical water at 350 bar. Carbon balance and hydrogen yield potential in an inert bed of $\mathrm{ZrO}_{2}$ particles (solid symbols), and of $1 \% \mathrm{Ru} / \mathrm{ZrO} \mathrm{Z}_{2}$ catalyst (open symbols) at $510^{\circ} \mathrm{C}(\bullet, \bigcirc)$ and $550^{\circ} \mathrm{C}(\boldsymbol{\nabla}, \nabla)$. 


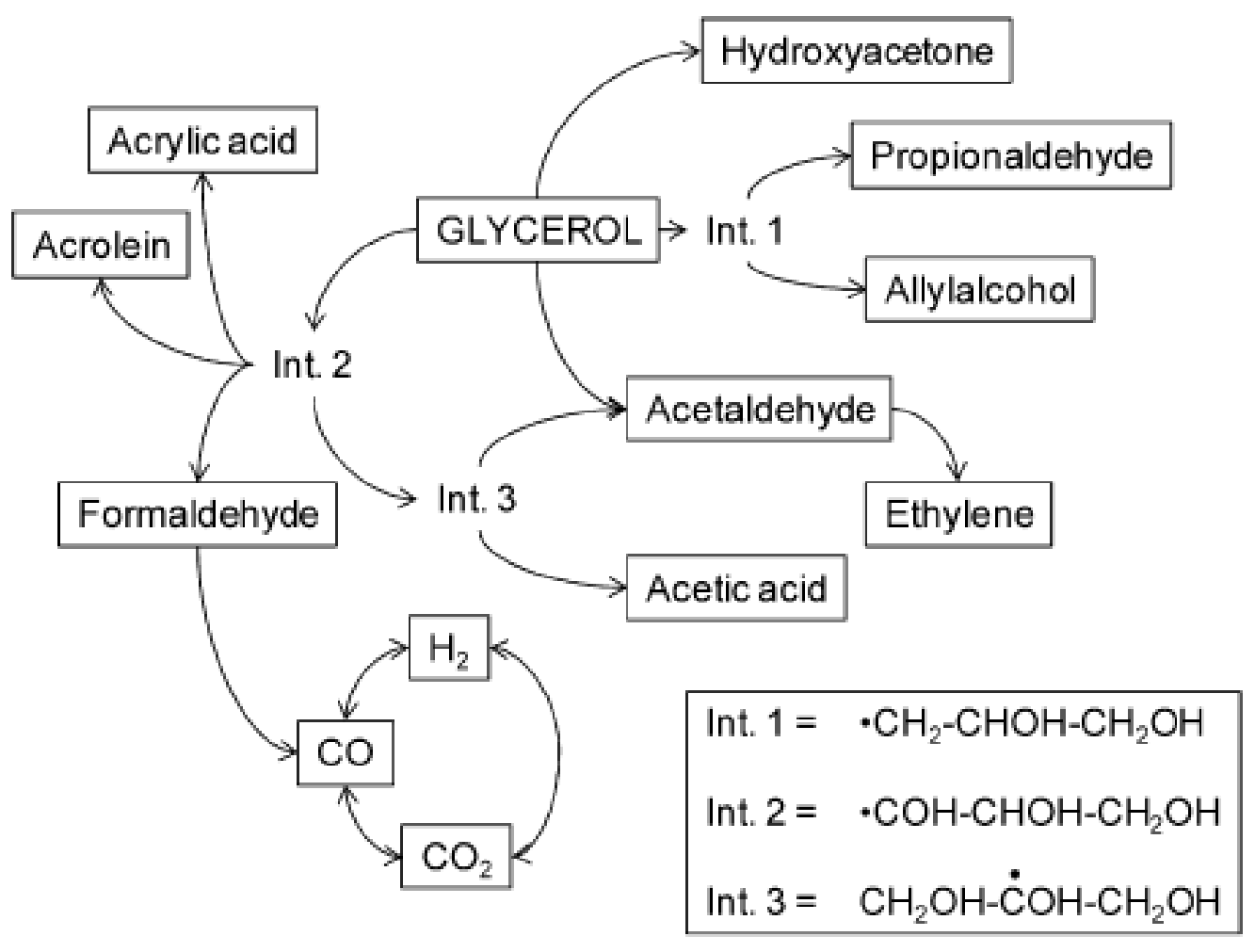

Figure 6. Simplified reaction pathways for glycerol hydrothermolysis in SCW. 


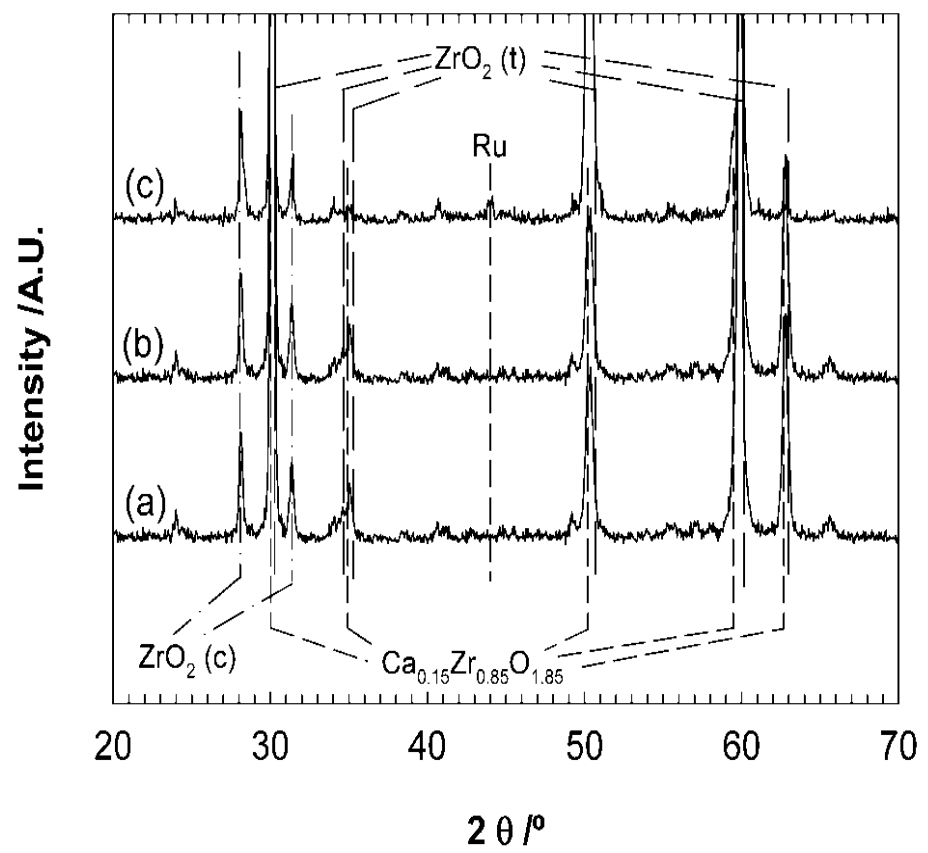

Figure 7. DRX spectra of samples of fresh $\mathrm{CaO}$-stabilized $\mathrm{ZrO}_{2}$ particles (a), zirconia particles after treatment in supercritical water at 350 bar and $450{ }^{\circ} \mathrm{C}$ for $22 \mathrm{~h}$ (b), and the $1 \% \mathrm{Ru} / \mathrm{ZrO} \mathrm{Z}_{2}$ catalyst (c). 

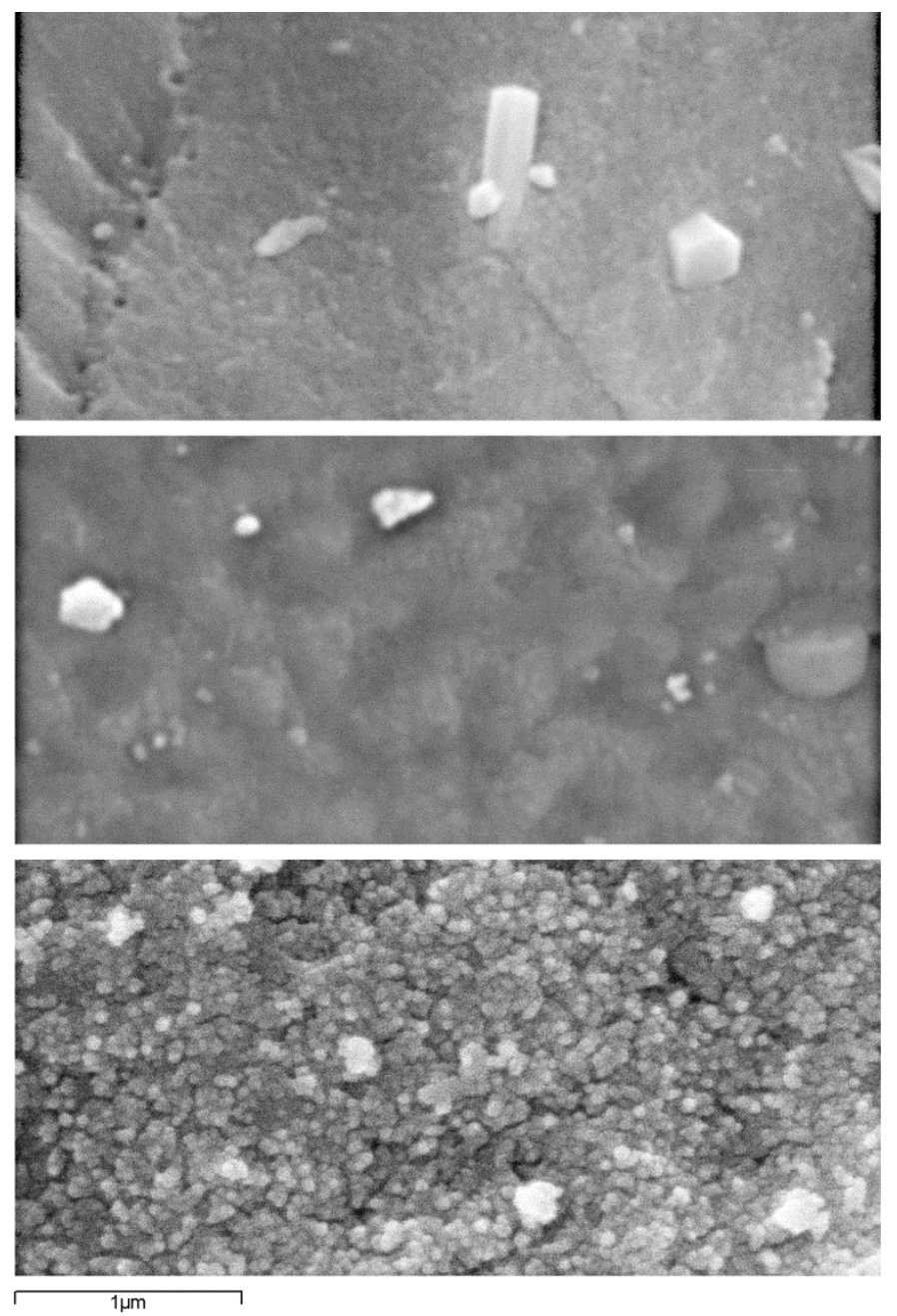

Figure 8. SEM images of the fresh $\mathrm{CaO}$-stabilized $\mathrm{ZrO}_{2}$ particles used as catalyst support (top), of the support particles after supercritical water treatment at 350 bar and $450{ }^{\circ} \mathrm{C}$ for $22 \mathrm{~h}$ (middle), and of the $1 \% \mathrm{Ru} / \mathrm{ZrO}_{2}$ catalyst (bottom). 

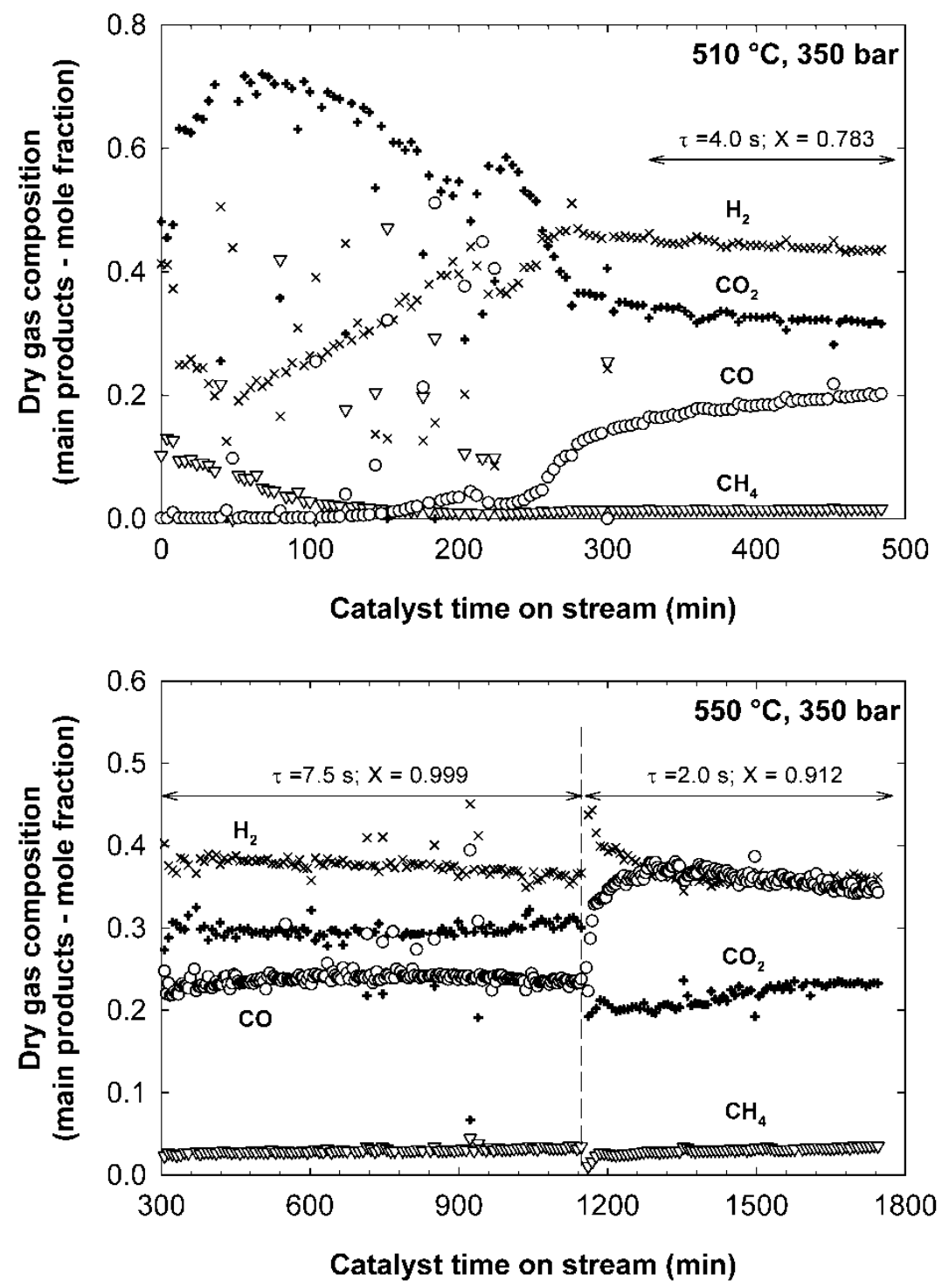

Figure 9. Extended experiments with the $1 \% \mathrm{Ru} / \mathrm{ZrO}_{2}$ catalyst. Processing of a $5 \%$ glycerol solution at 350 bar and $510^{\circ} \mathrm{C}$ on a fresh sample of catalyst (top), and at $550{ }^{\circ} \mathrm{C}$ with a conditions catalyst. 